\title{
Comparative Assessment of Fetal Malnutrition by Anthropometry and CAN Score with associated maternal factors in Sub-District hospital of Uttarakhand
}

\author{
Nikhurpa M. $^{{ }^{*}}{ }^{*}$, Nikhurpa V. $^{2}$, Pangty S. ${ }^{3}$ \\ DOI: https://doi.org/10.17511/ijpr.2021.i02.03
}

1* Mamta Nikhurpa, Pediatrician, District Hospital, Bageshwar, Uttarakhand, India.

2 Vinita Nikhurpa, Physician, Base Hospital, Haldwani, Uttarakhand, India.

3 Sandeep Pangty, Anesthesiologist, Female Hospital, Haldwani, Uttarakhand, India.

Introduction: Fetal malnutrition is an important contributor to perinatal mortality and morbidity. This study was aimed to assess the nutritional status of the newborn at birth using Clinical Assessment of Nutrition (CAN score) and compare it with other conventional anthropometric indices. In addition to studying maternal variables associated with fetal malnutrition. Material and Methods: This prospective study was conducted at Sub-District hospital, Uttarakhand for a 3-month duration from June 2020 to August 2020. Total 765 term, singleton newborn without major congenital malformation or comorbidities were included in the study. Anthropometric indices and CAN score were assessed and compared. Results: The incidence of fetal malnutrition was $17.39 \%$ using the CAN score. Fetal malnutrition was detected in 133(17.3\%), 65(8.5\%), 141(18.4\%), $91(11.8 \%), 85(11.1 \%)$ of newborn using CAN score, PI, Gestational age, BMI, and MAC/HC respectively. Out of clinically malnourished babies identified by CAN score, PI, gestational age, BMI and $\mathrm{MAC} / \mathrm{HC}$ identified $49.23 \%(32), 76.6 \%(108), 56.04 \%(51), 49.41 \%(42)$ as fetal malnutrition. BMI has the highest sensitivity and diagnostic accuracy for detecting fetal malnutrition. Maternal variables associated with FM include early maternal age during conception $81.4 \%$ (623), primigravida $33.1 \%(112)$, anemia $(21 \%)$, irregular antenatal checkups $(40 \%)$ and concurrent illnesses (PIH, urinary tract infection, heart disease, renal disease, vascular disease) $(50.9 \%)$. Conclusion: CAN score is a simple, handy and cost-effective tool to identify FM. Using BMI with CAN score can serve for screening FM. Among maternal variables, primigravida (33.1), anemia $(21.5 \%)$, irregular antenatal checkup $(40.25 \%)$, Concurrent medical illnesses $(50.96 \%)$ is strongly associated with FM. Maternal age is not statistically significant.

Keywords: Fetal malnutrition, CAN score, Ponderal index, Body mass index, Maternal factors

Corresponding Author

Mamta Nikhurpa, Pediatrician, District Hospital, Bageshwar, Uttarakhand, India.

Email: mamtanikhurpa389@gmail.com
How to Cite this Article

Nikhurpa M, Nikhurpa V, Pangty S. Comparative Assessment of Fetal Malnutrition by Anthropometry and CAN Score with associated maternal factors in Sub-District hospital of Uttarakhand. Pediatric Rev Int J Pediatr Res. 2021;8(2):82-87.

Available From

https://pediatrics.medresearch.in/index.php/ijpr/arti cle/view/664
To Browse

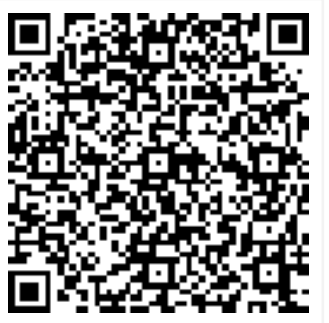

Manuscript Received 2021-03-23

Conflict of Interest No
Review Round 1 2021-04-08

Funding
Review Round 3

Riew Round

Ethical Approval Yes
Plagiarism X-checker $9 \%$
Accepted 2021-04-18

Note

(c) 2021 by Mamta Nikhurpa, Vinita Nikhurpa, Sandeep Pangty and Published by Siddharth Health Research and Social Welfare Society. This is an Open Access article licensed under a Creative Commons Attribution 4.0 International License https://creativecommons.org/licenses/by/4.0/ unported [CC BY 4.0]. 


\section{Introduction}

Birth weight and gestational age is an important factor for neonatal survival. Birth weight is governed by two major processes: duration of gestation and intrauterine growth rate [1] Clinical assessment of nutrition at birth is done by anthropometry (Birth weight, length, head circumference and chest circumference) and proportionality indices like ponderal index $[\mathrm{PI}]$, head circumference to length ratio, chest circumference or mid-arm circumference ratio and/or mid-arm circumference to head circumference [MAC: $\mathrm{HC}$ ] ratio [2]

It is however unlikely that these indices are sufficiently sensitive in identifying infants with clinically evident FM as it does not indicate the overall nutritional status of the baby. Fetal malnutrition (FM) can occur even in AGA infants and fetal malnutrition may not be present in SGA infants [3]

The global incidence of FM is between $2-10 \%$ of total birth especially in underprivileged communities [6] Studies have found that perinatal problems and CNS sequel occurred primarily in those with malnutrition, whether AGA or SGA [3-5] Among the contributory maternal variables associated with fetal malnutrition includes poverty, health neglect of females, early age of marriage, poor birth spacing, maternal malnutrition, anemia, infections.

Fetal malnutrition (FM) is a term coined by Scott and Usher in 1966 to describe infants who showed evidence of soft tissue wasting at birth irrespective of the specific etiology and is independent of birth weight and gestational age. It is defined as failure to acquire adequate quantum of fat and muscle mass due to poor nutrition in-utero resulting from inadequate supply and/or utilization of nutrient. [4]

FM can be clinically assessed by using the "Clinical Assessment of Nutritional Status (CAN) Score as described by metcoff in 1994 [3] CAN score consist of nine superficial readily detectable signs of nutritional status to be assessed within 48 hours to differentiate between well-nourished and malnourished neonates.

This study was aimed to assess the nutritional status of term newborns at birth using Clinical Assessment of Nutritional status score (CAN) and to compare the efficiency of CAN score and other anthropometric indices in identifying $F M$ in term newborns.

\section{Material and Methods}

Type of study: Prospective pilot study

Place of Study: Sub-District female Hospital, Haldwani (Uttarakhand) conducted for 3 months duration from 1st June 2020 to 31st August 2020.

Inclusion criteria: Term singleton newborns delivered consecutively in the hospital during the study period.

Exclusion criteria: Newborns $<37$ completed weeks gestation, associated with congenital anomalies, requiring intensive care, those born to mothers with Gestational Diabetes mellitus, multiple pregnancies, mothers with an unreliable estimation of gestational age.

Statistical analysis: Data analyzed using SPSS software version 21.0 . The comparison of variables was analyzed using the Chi-Square test/Fisher's exact test. For statistical significance $p$-value less than 0.05 was considered significant.

The following parameters were recorded in all babies (weight was recorded at birth, length, mid

Arm circumference and head circumference were recorded between $24-48$ hrs of life):

(I) Birth weight: measured using an electronic weighing scale (to the nearest $10 \mathrm{gms}$ )

(Ii) Crown to Heel Length: measured using an infantometer (to the nearest $0.1 \mathrm{~cm}$ )

(Iii) Occipito-frontal circumference: measured using flexible non-stretchable tape (to the nearest $0.1 \mathrm{~cm}$ )

(Iv) Mid Arm Circumference: Measured in the left arm, at a point midway between the tip of the

The acromion and the olecranon process using a flexible non-stretchable tape to the nearest $0.1 \mathrm{~cm}$.

These measurements (birth weight and length)were then plotted on intrauterine growth charts

To classify the newborns into, SGA and large for gestational age (LGA) [7]

Ponderal index(PI): It was calculated using the following formula

$\mathrm{PI}=$ Weight $(\mathrm{gms}) \times 100 /$ Length $(\mathrm{cms}) 3$

A ponderal index of less than $2.2 \mathrm{gm} / \mathrm{cm} 3$ was considered as an index of malnutrition [7].

Mid arm circumference/head circumference 
Ratio(MAC/HC): A cut off value of 0.27 was used in this study to define malnutrition [8].

Body mass index (BMI) was calculated using theformula:BMI = Weight $(\mathrm{Kg}) /$ Length $(\mathrm{m}) 2$

A cutoff value of $11.20 \mathrm{~kg} / \mathrm{m} 2$ was considered as an index of malnutrition [9].

Newborns were assessed clinically based on the superficial readily detectable signs of malnutrition in the newborn using the clinical assessment of nutrition (CAN) rating as described by Metcoff [3]. Each attribute was scored based on specific described criteria from 1 to $4 ; 1$ denotes evidence of fetal malnutrition and 4 being the evidence of good nutrition. The CAN score ranges between 9 as the lowest score and 36 as the highest score. Any score less than 25 suggestive of malnutrition.

\section{Results}

In the present study total number of newborns included after fulfilling inclusion and exclusion criteria were $765(n=765)$ out of which $362(47.3 \%)$ were female and 403(52.6\%) were male. There was a slight male preponderance which is statistically significant. The incidence of fetal malnutrition was $17.39 \%$ using CAN score, among which 68 $(18.78 \%)$ were female and $65(16.13 \%)$ were male. (Table 1)In the present study mean birth weight of newborns was $2890 \pm 40 \mathrm{gm}$; the mean length was $48.16 \pm 2.16 \mathrm{~cm}$. Comparing the gestational age $141(18.3 \%)$ neonate were SGA whereas 624 $(81.5 \%)$ were AGA. The incidence of malnutrition using various anthropometric parameters and results were calculated. Out of 765 newborns, $85(11.1 \%)$ were low birth weight $(<2.5 \mathrm{~kg}), 141$ were small for gestational age (18.4\%). 8.5\% (65) newborn has ponderal index less than 2.2. Low BMI was seen in 91 newborns (11.8\%). 85 newborns $(11.1 \%)$ have low MAC/HC. As per CAN score 133 newborns were detected clinically malnourished accounting for $17.3 \%$ (Table 2 )
Based on the ponderal index and 8.5\% (65) of the newborns were malnourished. Upon CAN score assessment, $50.7 \%$ (33) were found clinically well nourished and of the remaining well-nourished neonates with normal PI, $14.4 \%$ (101) had significant malnutrition (Table 3 )

On classifying the newborns based on BMI,11.8\% (91) newborns were malnourished. But when assessed by their CAN score, $43.9 \%$ (40) of these newborns were well nourished. On the other hand newborns with a normal BMI of $12.1 \%$ (82) had signs of malnutrition by CAN score which were found to be statistically significant (Table 3)

Based on MAC/HC, $11.1 \%$ (85) newborns were found malnourished. Among these 50.5\% (43) were identified as well-nourished by CAN score and $13.3 \%$ (91) newborns with normal MAC/HC ratio were clinically malnourished (Table 3 ).

Table 1: Comparison of CAN score between gender

\begin{tabular}{|c|c|c|c|c|c|}
\hline $\begin{array}{l}\text { CAN } \\
\text { score }\end{array}$ & $\begin{array}{l}\text { Female } \\
(n=362)\end{array}$ & $\begin{array}{c}\text { Male } \\
(n=403)\end{array}$ & Total & \begin{tabular}{|c|}
$P$ \\
value
\end{tabular} & Testperformed \\
\hline$<25$ & $68(18.78 \%)$ & $\begin{array}{l}65 \\
(16.13 \%)\end{array}$ & $\begin{array}{l}133 \\
(17.39 \%)\end{array}$ & \multirow[t]{3}{*}{0.333} & \multirow[t]{3}{*}{$\begin{array}{l}\text { Chi-square } \\
\text { test, } 0.936\end{array}$} \\
\hline$>=25$ & $294(81.22 \%)$ & $\begin{array}{l}338 \\
(83.87 \%)\end{array}$ & $\begin{array}{l}632 \\
(82.61 \%)\end{array}$ & & \\
\hline Total & $362(100 \%)$ & $403(100 \%)$ & $\begin{array}{l}765 \\
(100 \%)\end{array}$ & & \\
\hline
\end{tabular}

Table 2: Incidence of malnutrition using various anthropometric parameters

\begin{tabular}{|l|l|l|l|}
\hline \multicolumn{1}{|c|}{ Parameter } & Normal & Malnourished & Incidence \\
\hline Birth weight & 680 & 85 & $11.1 \%$ \\
\hline Ponderal index & 700 & 65 & $8.5 \%$ \\
\hline Body Mass index & 674 & 91 & $11.8 \%$ \\
\hline MAC/HC & 680 & 85 & $11.1 \%$ \\
\hline CAN score & 632 & 133 & $17.3 \%$ \\
\hline
\end{tabular}

Table 3: Comparison of body indices between CAN score

\begin{tabular}{|c|c|c|c|c|c|}
\hline Body indices & CAN score $<25(n=133)$ & CAN score $>=25(n=632)$ & Total & $P$ value & Testperformed \\
\hline \multicolumn{6}{|c|}{ Ponderal index $\left(\mathrm{gm} / \mathrm{cm}^{3}\right)$} \\
\hline$<2.2$ & $32(49.23 \%)$ & $33(50.77 \%)$ & $65(100 \%)$ & \multirow[t]{2}{*}{$<.0001$} & \multirow[t]{2}{*}{ Chi square test, 50.155} \\
\hline$>=2.2$ & $101(14.43 \%)$ & 599 (85.57\%) & $700(100 \%)$ & & \\
\hline \multicolumn{6}{|c|}{ Body mass index $\left(\mathrm{kg} / \mathrm{m}^{2}\right)$} \\
\hline$<11.2$ & $51(56.04 \%)$ & $40(43.96 \%)$ & $91(100 \%)$ & \multirow[t]{2}{*}{$<.0001$} & \multirow[t]{2}{*}{ Chi square test, 107.469} \\
\hline$>=11.2$ & $82(12.17 \%)$ & $592(87.83 \%)$ & $674(100 \%)$ & & \\
\hline
\end{tabular}


Nikhurpa M. et al: Comparative Assessment of Fetal Malnutrition

\begin{tabular}{|l|l|l|l|l|l|}
\hline$<0.27$ & $42(49.41 \%)$ & $43(50.59 \%)$ & $85(100.00 \%)$ & $<.0001$ & Chi square test, 68.287 \\
\hline$>=0.27$ & $91(13.38 \%)$ & $589(86.62 \%)$ & $680(100.00 \%)$ & & \\
\hline
\end{tabular}

\section{Table 4:-Comparison of maternal factors between CAN score}

\begin{tabular}{|c|c|c|c|c|c|}
\hline Maternal factors & CAN score $<25(n=133)$ & CAN score $>=25(n=632)$ & Total & $P$ value & Testperformed \\
\hline \multicolumn{6}{|l|}{ Age(years) } \\
\hline$<30$ & $109(17.50 \%)$ & $514(82.50 \%)$ & $623(100 \%)$ & \multirow[t]{2}{*}{0.866} & \multirow[t]{2}{*}{ Chi-square test, 0.028} \\
\hline$>=30$ & $24(16.90 \%)$ & $118(83.10 \%)$ & $142(100 \%)$ & & \\
\hline \multicolumn{6}{|l|}{ Parity } \\
\hline Primi & $112(33.14 \%)$ & $226(66.86 \%)$ & $338(100 \%)$ & \multirow[t]{2}{*}{$<.0001$} & \multirow[t]{2}{*}{ Chi square test, 104.59} \\
\hline Multi & $21(4.92 \%)$ & $406(95.08 \%)$ & $427(100 \%)$ & & \\
\hline \multicolumn{6}{|l|}{ Hemoglobin levels } \\
\hline$<11$ & $65(21.52 \%)$ & $237(78.48 \%)$ & $302(100 \%)$ & \multirow[t]{2}{*}{0.015} & \multirow[t]{2}{*}{ Chi square test, 5.947} \\
\hline$>=11$ & $68(14.69 \%)$ & $395(85.31 \%)$ & $463(100 \%)$ & & \\
\hline \multicolumn{6}{|l|}{ Antenatal check ups } \\
\hline Irregular & $130(40.25 \%)$ & $193(59.75 \%)$ & $323(100 \%)$ & \multirow[t]{2}{*}{$<.0001$} & \multirow[t]{2}{*}{ Fisher Exact test } \\
\hline Regular & $3(0.68 \%)$ & $439(99.32 \%)$ & $442(100 \%)$ & & \\
\hline \multicolumn{6}{|c|}{ Concurrent medical illness } \\
\hline No & $80(12.10 \%)$ & $581(87.90 \%)$ & $661(100 \%)$ & \multirow[t]{2}{*}{$<.0001$} & \multirow[t]{2}{*}{ Chi square test, 94.472} \\
\hline Yes & $53(50.96 \%)$ & $51(49.04 \%)$ & $104(100 \%)$ & & \\
\hline
\end{tabular}

Table 5:-Sensitivity, specificity, PPV and NPV of body indices to predict malnutrition

\begin{tabular}{|c|c|c|c|c|c|c|}
\hline $\begin{array}{c}\text { Taking CAN score as a } \\
\text { reference }\end{array}$ & $\begin{array}{l}\text { Sensitivity }(95 \% \\
\text { CI) }\end{array}$ & $\begin{array}{c}\text { Specificity }(95 \% \\
\text { CI })\end{array}$ & $\begin{array}{l}\text { AUC }(95 \% \\
\text { CI })\end{array}$ & $\begin{array}{l}\text { Positive Predictive } \\
\text { Value }(95 \% \mathrm{CI})\end{array}$ & $\begin{array}{c}\text { Negative Predictive } \\
\text { Value }(95 \% \text { CI })\end{array}$ & $\begin{array}{l}\text { Diagnostic } \\
\text { accuracy }\end{array}$ \\
\hline Ponderal index $\left(\mathrm{gm} / \mathrm{cm}^{3}\right)$ & $\begin{array}{l}24.6 \%(17.08 \% \text { to } \\
32.23 \%)\end{array}$ & $\begin{array}{l}94.78 \%(92.74 \% \text { to } \\
96.38 \%)\end{array}$ & $\begin{array}{l}0.59(0.56 \text { to } \\
0.63)\end{array}$ & $\begin{array}{l}49.23 \%(36.60 \% \text { to } \\
61.93 \%)\end{array}$ & $85.57 \%(82.75 \%$ to $88.09 \%)$ & $82.48 \%$ \\
\hline Body mass index $\left(\mathrm{kg} / \mathrm{m}^{2}\right)$ & $\begin{array}{l}38.35 \%(30.05 \% \text { to } \\
47.17 \%)\end{array}$ & $\begin{array}{l}93.67 \%(91.48 \% \text { to } \\
95.44 \%)\end{array}$ & $\begin{array}{l}0.66(0.63 \text { to } \\
0.69)\end{array}$ & $\begin{array}{l}56.04 \%(45.25 \% \text { to } \\
66.44 \%)\end{array}$ & $87.83 \%(85.12 \%$ to $90.21 \%)$ & $84.05 \%$ \\
\hline $\mathrm{MAC} / \mathrm{HC}(\mathrm{cm})$ & $\begin{array}{l}31.58 \%(23.80 \% \text { to } \\
40.20 \%)\end{array}$ & $\begin{array}{l}93.20 \%(90.94 \% \text { to } \\
95.03 \%)\end{array}$ & $\begin{array}{l}0.62(0.59 \text { to } \\
0.66)\end{array}$ & $49.41 \%(38.39 \%$ to $60.48 \%)$ & $86.62 \%(83.83 \%$ to $89.09 \%)$ & $82.48 \%$ \\
\hline
\end{tabular}

On assessing maternal variables early maternal age during conception $81.4 \%$ (623), primigravida $33.1 \%$ (112), anemia $(21 \%)$, irregular antenatal checkups (40\%) and associated concurrent illnesses (PIH, urinary tract infection, heart disease, renal, vascular disease) (50.9\%) were associated with increased risk for fetal malnutrition (Table 4)

\section{Discussion}

Low birth weight is a major public health problem in India with an incidence of $30 \%$. LBW infants have a greater risk of short term and long term morbidity. This study aims to identify the incidence of fetal malnutrition, to compare different methods of assessment for malnutrition and to study maternal variables associated with fetal malnutrition. Fetal malnutrition is a term coined by Scott and Usher, which indicates a clinical state that may be present irrespective of birth weight, gestational age (AGA), intrauterine growth retardation (IUGR) or small for gestational age (SGA) categories [4].
The incidence of fetal malnutrition in our study is $17.39 \%$ similar to Adebami et al [10] (18.8\%), Vikram Singhal et al [11] (17.5\%) as compare to metcoff [3] (10.9\%) Soundarya et al [2](24\%), Dhanorkar et all [12] (32.29\%), Sankhyan et al [13] $(27.97 \%)$. The variability is expected as it depends upon population studies, growth curve used and sample size. CAN score identified 133 newborns $(17.39 \%)$ to be malnourished compared to $65(8.5 \%)$ by ponderal index, 91 (11.8\%) by BMI, $85(11.1 \%)$ by MAC/HC. Using CAN score as the gold standard for identifying $F M$, sensitivity and specificity of the ponderal index is $24.6 \%$ and $94.7 \%$, for BMI is $38.3 \%$ and $93.6 \%$ and for $\mathrm{MAC} / \mathrm{HC}$ is $31.58 \%$ and $93.20 \%$ (Table 5) The sensitivity of the ponderal index is low in our study $24.6 \%(17.08 \%$ to $32.23 \%)$ with a low diagnostic accuracy of $82.48 \%$ for predicting fetal malnutrition. As it relies on the principle that the length is spared at the expense of weight during acute malnutrition, also it does not account for chronic malnutrition. 
BMI has a positive correlation with skinfold thickness and body fat mass [14]. In our study sensitivity of BMI is highest $(38.3 \%)$ similar to Soundarya et al [2] and Ezenwa et al [15] therefore it is also a sensitive indicator in predicting FM. Maternal risk factors are strongly associated with an increased risk of fetal malnutrition. In the present study most of the mothers (623) were of age less than 30 years $(81.4 \%)$ and only $142(18.5 \%)$ were more than 30 years old. A low number of cases in the at-risk group might be the reason for statistical insignificance (P-value 0.866$)$. Fetal malnutrition is more common in primigravida $(33.1 \%)$ as compare to multigravida mother (4.9\%) which is similar to Janardhan AM et al [16]. Maternal anemia $\mathrm{Hb}<11$ $(21.5 \%)$, irregular antenatal checkup (40.25\%) and concurrent medical illness (50.96\%) like Hypertension, Gestational Diabetes mellitus, urinary tract infection, Heart diseases, renal disease is associated with increased risk of fetal malnutrition and is statistically significant.

\section{Conclusion}

Fetal malnutrition is an important contributor to perinatal mortality and morbidity and requires careful observation and documentation for early intervention for intact survival of the newborn.CAN score is a simple, handy and cost-effective tool to detect fetal malnutrition. It measures visible wasting observed in malnourished newborn. CAN score also identify full-term AGA malnourished newborn those are considered normal if we consider only weight criteria. Also our study observed a strong association of Primiparity, anemia, irregular antenatal checkup, concurrent medical illness and maternal age with fetal malnutrition.

\section{What does this study add to existing knowledge?}

Comparative analysis of CAN score with other anthropometric indices shown CAN score to be an easy, cost-effective and statistically superior for screening fetal malnutrition for optimizing resourcelimited developing countries. Also our study showed a major association of maternal variables with fetal malnutrition which are preventable with good antenatal care.

\section{Acknowledgements}

The authors would like to thank all the babies and their mothers for participating in the study

\section{Contributors Details}

MN: conceptualized, manuscript preparation, acquisition, literature research and statistical analysis; VN,

SP: analysis, manuscript editing and review, provided intellectual inputs to the manuscript; $M N$ is the guarantor for this paper.

\section{Reference}

01. Battaglia FC, Lubchenco LO. A practical classification of newborn infants by weight and gestational age. J Pediatr. 1967;71(2)159-63.

[Crossref]

02. Soundarya M, Basavaprabhu A, Raghuveera K, et al. Comparative Assessment of Fetal Malnutrition by Anthropometry and CAN Score. Iran J Pediatr. 2012 Mar;22(1)70-6.

[Crossref]

03. Metcoff J. Clinical assessment of nutritional status at birth, Fetal malnutrition and SGA are not synonymous. Pediatr Clin North Am. 1994 Oct;41(5)875-91.

[Crossref]

04. Scott KK, Usher RH. Fetal malnutritionIncidence, causes and effects. Amer J Obstetr. 1966;94(7)951-63.

[Crossref]

05. Jayant D, Rajkumar J. Study of the prevalence and high-risk factors for fetal malnutrition in term newborns. Ann Trop Paediatr. $1999 ; 19 ; 273-77$.

[Crossref]

06. Crosby WM. Studies in fetal malnutrition. Am J Dis Child. 1991;145;871-6.

[Crossref]

07. Mohan M, Prasad SR, Chellani HK, et al. Intrauterine growth curves in North Indian babies- weight, length, head circumference and Ponderal index. Ind Pediatr. 1990;27(1)43-51. [Crossref]

08. Georgieff MK, Sasanow SR, Chockalingam UM, et al. A comparison of midarm circumference/head circumference ratio and Ponderal index for evaluation of mentally retarded infants after abnormal intrauterine growth. Acta Pediatr Scand. 1988;77(2)214-9. [Crossref] 
09. Brock RS, Falcao MC, Leone C. Body mass index values for newborns according to gestational age. Nutr Hosp. 2008;23(5)487-92.

[Crossref]

10. Adebami OJ, Owa JA, Oyedeji GA, et al. Prevalence and problems of fetal malnutrition in term babies at Wesley Guild Hospital, South Western Nigeria. West Afr J Med. 2007;26(4)278-82.

[Crossref]

11. Vikram singhal, Prashanth Agal, Nutan Kamath. Detection of Fetal Malnutrition by CAN score at birth and its comparison with other methods of determining Intrauterine Growth. Indian Journal of Clinical Practice. April 2012;22(11)576-82.

[Crossref]

12. Abhaykumar Dhanorkar, Prashant Bagdey, Arun Humne. Detection of Fetal Malnutrition at birth by clinical assessment of nutritional status score. Health sciences- An International Journal. 2014;4(1)1-5.

[Crossref]
13. Sankhyan N, Sharma VK, Singh S. Detection of fetal malnutrition using "CAN score". Indian J Pediatr. 2009 Sep;76(9)903-6.

doi: 10.1007/s12098-009-0196-9 [Crossref]

14. Carrera JM, Devesa R, Salvador J. Aetiology and pathogenesis of intrauterine growth restriction, In- Kurjak A, editor, Textbook of Perinatal Medicine. London- Parthenon Publishing. 1998; 1171-91.

[Crossref]

15. Ezenwa BN, Iroha EO, Ezeaka VC, Egri-Okwaji MT. Comparative study of Clinical Assessment of Nutritional status score and proportionality indices in the assessment of fetal malnutrition in term newborns. Niger Med J. 2016;57;124-8. doi: $10.4103 / 0300-1652.182075$ [Crossref]

16. Janardhan AM et al. Detection of fetal malnutrition and its associated maternal factors in a rural setting. Int J Contemp Pediatr. 2020 Sep;7(9)1880-1884, DOI: 10. 18203/2349-3291.ijcp20203647 [Crossref] 